25. Lowry, O. H., Rosebrough, N. J., Farr, A. L., and Randall, R. J.: Protein measurement with the Folin phenol reagent. J. Biol. Chem., 193: 265 (1951)

26. Mangos, J. A., McSherry, N. R., and Benke, P. J.: A sodium transport inhibitory factor in the saliva of patients with cystic fibrosis of the pancreas. Pediat. Res., 1: 436 (1967).

27. Mangos, J. A., and Talamo, R. C.: Ciliary inhibitor factor of cystic fibrosis, p. 2 (National Cystic Fibrosis Research Foundation, Gap Conference Report, Atlanta, 1973).

28. Posselt, H. G., and Bender, S.: Heterozygote testing in cystic fibrosis: Experimental studies with cilia of the mussel Dreissena polymorpha. Z. Kinderheilk., 110: 98 (1971).

29. Skou, J. C. Enzymatic basis for active transport of $\mathrm{Na}^{+}$and $\mathrm{K}^{+}$across cell membrane. Physiol. Rev., 45: 596 (1965).

30. Spock, A., Heick, H. M. C., Cress, H., and Logan, W. S.: Abnormal serum factor in patients with cystic fibrosis of the pancreas. Pediat. Res., $l: 173$ (1967).

31. Taylor, H., Mayo, J. W., Boat, T. F., and Matthews, L. W.: Standardized assay for the sodium reabsorption inhibitory effect and studies of its salivary gland distribution in patients with cystic fibrosis. Pediat. Res., 8: 861 (1974).

32. Warner, F. D.: Macromolecular organization of eukaryotic cilia and flagella. Advan. Cell. Mol. Biol., 2: 193 (1972).

33. Wachstein, M., Meisel, E., and Niedzwiedz, A.: Histochemical demonstration of mitochondrial adenosine triphosphatase with the lead adenosine triphosphate technique. J. Histochem. Cytochem., 8: 387 (1960).

34. Watanabe T., and Flavin, M.: Two types of adenosine triphosphate from flagella

Copyright $(1976$ International Pediatric Research Foundation, Inc. of Chlamydomonas reinhardi. Biochem. Biophys. Res. Commun., 52: 195 (1973).

35. Wetzel, M. G., Wetzel, B. K., and Spicer, S. S.: Ultrastructural localization of acid mucosubstances in the mouse colon with iron-containing stains. J. Cell. Biol., 30: 299 (1966).

36. Wood, R. E., and di Sant'Agnese, P. A.: Bioassays of cystic fibrosis factor. Lancet, ii: 1452 (1973).

37. Eppendorf pipette, Brinkman Instruments, Inc., Westbury, N. Y

38. ICN Pharmaceuticals, Inc., Irvine, Calif.

39. Kodak N. S. medical x-ray film. Eastman Kodak Co., Rochester, N. Y

40. New England Nuclear, Boston, Mass

41. Gift of Dr. Robert S. Adelstein, National Heart and Lung Institute, National Institutes of Health, Bethesda, Md.

42. Informed consent was obtained from subjects participating in this study.

43. We thank Dr. Paul A. di Sant'Agnese, Chief. Pediatric Metabolism Branch NIAMDD, for his support and guidance in all phases of this study and Anthony J. Adams, Marta M. Ulane, and Judith M. Podskalny for skilled technical help. The valuable assistance of Dr. Robert E. Wood, University Hospitals of Cleveland, Dr. James H. Conover, Mount Sinai School of Medicine, and Mr. Harold Davis, Maryland Department of Natural Resources, is also gratefully acknowledged.

44. Requests for reprints should be addressed to: P. M. Farrell, M.D., Ph.D., Neonatal and Pediatric Medicine Branch, National Institute of Child Health and Human Development, National Institutes of Health, Bldg. 10, Rm. 13 N260, Bethesda, Md. 20014 (USA)

45. Accepted for publication Oct. 14, 1975

Pediat Res. 10: 135-139 (1976)

Cardiac refractory periods electrophysiology

Printed in U.S.A.

\title{
The Influence of Age on Cardiac Refractory Periods in Man
}

\author{
IRA W. DuBROW, ${ }^{(30)}$ ElIZABETH A. FISHER, PABLO DENES, AND ALOIS R. HASTREITER \\ Sections of Pediatric and Adult Cardiology, University of Illinois Hospital and Abraham Lincoln School of \\ Medicine, Chicago, Illinois, USA
}

\section{Extract}

As age is a determinant of cardiac refractory periods, this communication describes changes of refractory periods in an age continuum of infants, children and adults, 7 months through 77 years. Seventy patients with evidence of normal A-V conduction on scalar electrocardiogram were included. The patients were divided into six age groups: $<2$ years, 3-5 years, 6-10 years, 11-15 years, 16-30 years, and $>30$ years. Extrastimulus technique was used to determine refractory periods in sinus rhythm or at longest cycle length assuring atrial capture, then at shorter cycle lengths. Cycle lengths $(C L)$ for each age group were divided into ranges: $C L_{1}$, 1,000-600 msec; $\mathrm{CL}_{2}, 599-460 \mathrm{msec} ; \mathrm{CL}_{3},<459 \mathrm{msec}$. Refractory periods at the three CL's within each age group were determined. Full recovery times of the $\mathrm{A}-\mathrm{V}$ node within groups of children were determined. Statistical significance of the data was found by analysis of variance. The younger group tended to have shorter values than the older groups $(F<0.05-0.001)$.

\section{Speculation}

These changes with age apparently reflect maturation of the conduction system and may explain the differences in susceptibility to and electrophysiologic manifestations of various arrhythmias in infants, children, and adults.
Standard cardiac catheterization studies have contributed much to understanding hemodynamic and myocardial functions in pediatric patients. Recent advances in clinical intracardiac electrophysiology have lead to better understanding of normal and pathologic atrioventricular conduction, primarily in adults $(5,6$, $23,24,26)$. There is limited intracardiac electrophysiology data available for children $(1-4,21,22)$. DuBrow et al. (7) recently demonstrated shorter atrial and A-V nodal refractory periods in juveniles compared with adults at similar heart rates. This paper will expand our previously reported observations by examining cardiac refractory periods in multiple age groups.

\section{MATERIALS AND METHODS}

\section{PATIENT SELECTION}

Studies were performed in 70 patients, whose ages ranged from 7 months through 77 years, during diagnostic cardiac catheterization. Only patients with evidence of normal A-V conduction on scalar electrocardiogram were included (sinus rhythm, normal P-R interval, and narrow QRS). Clinical status, electrocardiographic diagnosis, and intracardiac electrogram intervals were reported previously $(5,7,26)$. Three additional children meeting the above criteria were included: two 8 year olds, one with a ventricular 
septal defect, the other with a coarctation of the aorta; and a 2.5 year old with endocardial fibroelastosis.

\section{ELECTROPHYSIOLOGIC PROCEDURE}

Patients and parents were informed of the nature of the study and a signed consent was obtained. No child was receiving cardioactive drugs, and only two adult patients received cardioactive drugs within 1 week before study (procaine amide and digoxin). In both, the drugs were discontinued $48 \mathrm{hr}$ before the study. Studies were performed in the postabsorptive, lightly sedated state in children and nonsedated state in adults after diagnostic cardiac catheterization.

Low atrial, His bundle, and ventricular electrograms were recorded with a multipolar catheter positioned across the tricuspid valve (24). High right atrial electrograms were recorded from the proximal electrodes of another multipolar catheter positioned in the high lateral right atrium, and distal electrodes of the same catheter were used for atrial pacing (5). Interelectrode distances
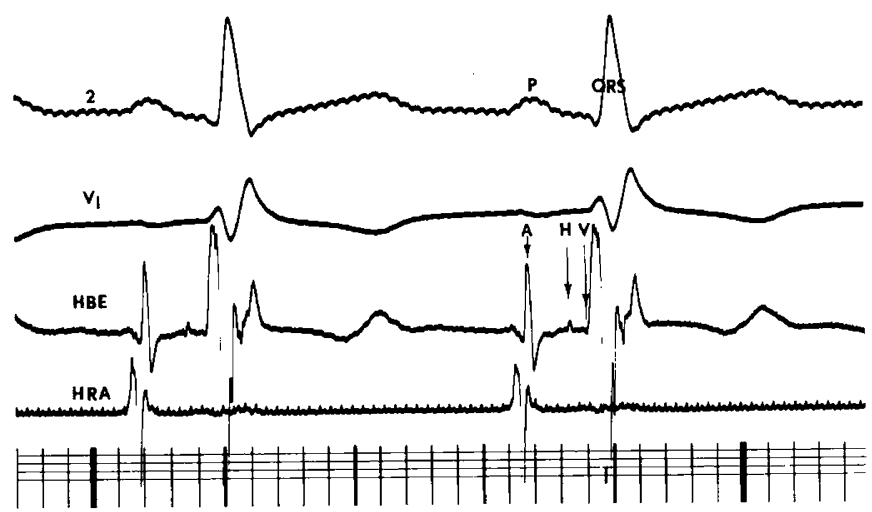

Fig. 1. Representative tracing from a 12-year-old child during sinus rhythm to demonstrate electrophysiologic events recorded at $200 \mathrm{~mm} / \mathrm{sec}$. 2 and $V_{1}$ are surface electrocardiogram leads. $P$ and QRS waves are labeled. HBE is the tracing from the multipolar catheter lying across the tricuspid valke to record low right atrial $(A)$, His bundle $(H)$ and ventricular $(V)$ electrograms. HRA is the tracing from the catheter placed at superior vena cava-right atrium junction. Atrial pacing and programmed extrastimuli are delivered via this catheter.

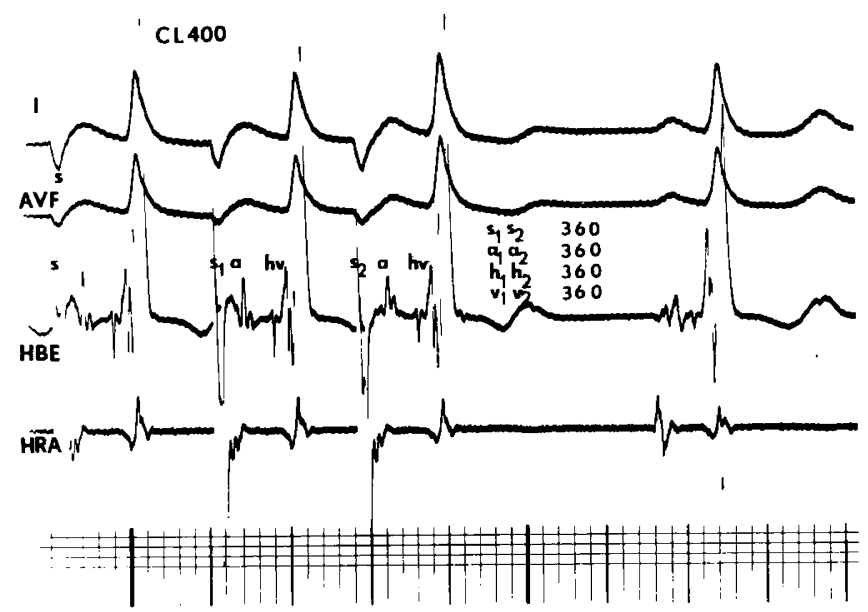

Fig. 2. Representative atrial extrastimulus tracing from a 2 -year-old child at an atrial driving rate of $400 \mathrm{msec}$ recorded at $100 \mathrm{~mm} / \mathrm{sec} .1$ and AVF are surface electrocardiograms; HBE and HRA are as described in Figure 1. $\mathrm{S}$ is the pacemaker stimulus artifact; $\mathrm{S}_{1}$ is the last stimulus before the programmed premature stimulus, $S_{\mathbf{2}}$. Corresponding intracardiac electrograms $(a, h$, and $v)$ follow $\mathrm{S}_{1}$ and $\mathrm{S}_{2}$. Early in the cycle scan $\mathrm{S}_{2}$ is introduced $360 \mathrm{msec}$ after $\mathrm{S}_{1}\left(S_{1} S_{2} 360\right)$ and $\mathrm{a}_{1} \mathrm{a}_{2}, \mathrm{~h}_{1} \mathrm{~h}_{2}, \mathrm{v}_{1} \mathrm{v}_{2}$ are $360 \mathrm{msec}$.
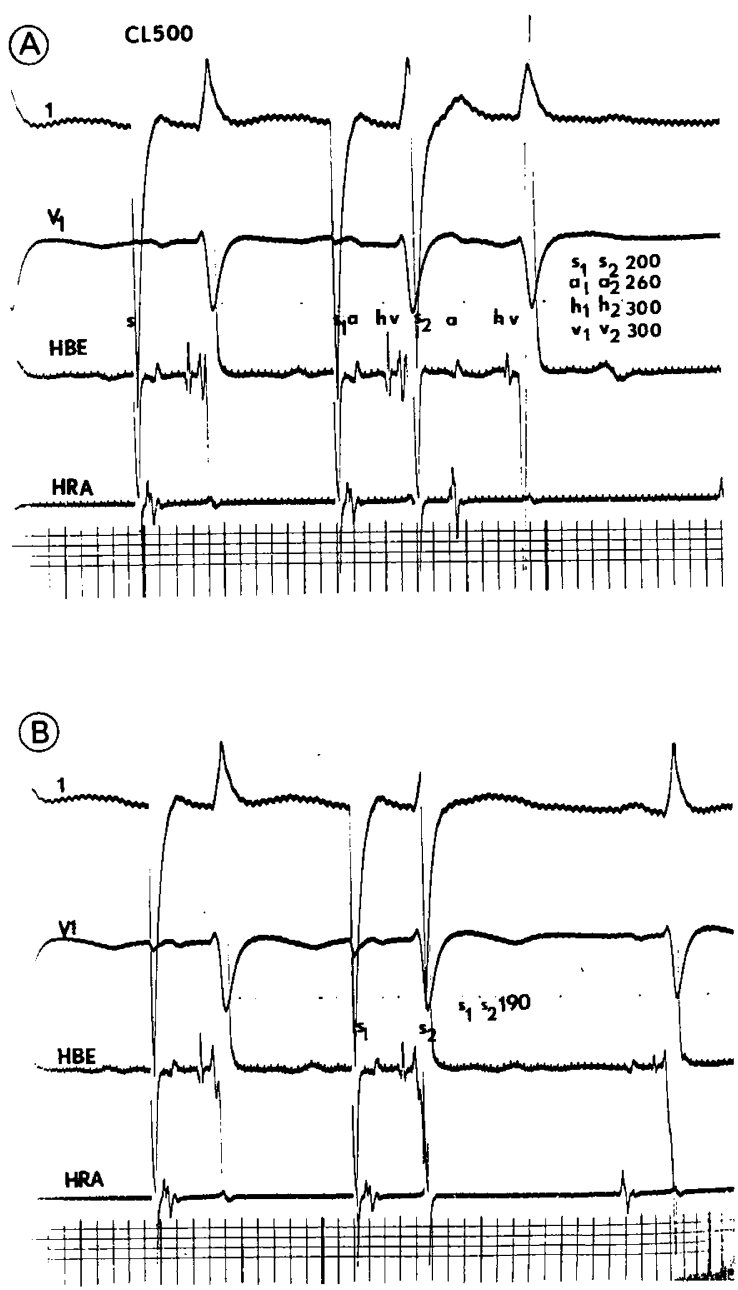

Fig. 3. $A$ : representative atrial extrastimulus tracing in a 5-year-old child during atrial pacing at cycle length $500 \mathrm{msec}(C L 500)$. 1 and $\mathrm{V}_{1}$ are surface electrocardiograms. HBE and HRA, $S_{1}, S_{2}, a, h$, and $v$ are as described in legends to Figures 1 and $2, S_{1} S_{2}$ is $200 \mathrm{msec}$. The shortest $a_{1} a_{2}$ obtained was $260 \mathrm{msec}$ (atrial functional refractory period). The $60-\mathrm{msec}$ delay between $S_{1} S_{2}$ and $a_{1} a_{2}$ represents atrial latency. $B$ : the next $10-\mathrm{msec}$ extrastimulus decrement in the same patient at the same driving rate as in $A$. No atrial electrogram follows $S_{2}$. This is the longest $S_{1} S_{2} 190$ mesc that does not conduct to the atrium (atrial effective refractory period). In this patient the conduction system is atrial limited. A-V node and His-Purkinje system refractory periods are equal to or less than atrial functional refractory period.

were $1-0.5 \mathrm{~cm}$. Intracardiac electrograms and at least two external ECG leads were displayed on an oscilloscope and recorded on a multichannel photographic recorder (Hewlett-Packard $4568 \mathrm{C}$ or Electronics for Medicine DR-16) at paper speeds of 100 and 200 $\mathrm{mm} / \mathrm{sec}$. Frequencies below $40 \mathrm{~Hz}$ and above $500 \mathrm{~Hz}$ were filtered for signal clarity. (Fig. 1). Pacing and premature stimuli were approximately twice diastolic threshold, $2 \mathrm{msec}$ in duration, and delivered by a programmable digital stimulator (27) through a stimulus isolator unit.

Extrastimulus technique was used to determine refractory periods first in sinus rhythm or at longest cycle length assuring atrial capture, then at shorter cycle length(s). The extrastimulus $\left(\mathrm{S}_{2}\right)$ was introduced at $10-20$-msec decrements after $8-10$ sinus or driven $\left(S_{1}\right)$ beats. Each patient had refractory periods determined at $1-5$ cycle lengths.

Intervals were measured as previously described $(5,7,26) . A_{1}$, $\mathrm{H}_{1}, \mathrm{~V}_{1}$ represent atrial, $\mathrm{His}$ bundle, and ventricular electrograms of either spontaneous or $S_{1}$-driven beats. $A_{2}, H_{2}$, and $V_{2}$ represent atrial, His bundle, and ventricular electrograms of the premature beat induced by $\mathrm{S}_{2}$ (Fig. 2). 


\section{DEFINITIONS}

Atrial effective refractory period was the longest $S_{1}-S_{2}$ at which atrial capture failed to occur. Atrial functional refractory period was the shortest $\mathrm{A}_{1}-\mathrm{A}_{2}$ attainable. (Fig. 3, $A$ and $B$ ). When the shortest coupling interval was too long to determine atrial effective refractory period or atrial functional refractory period, the value was said to be less than the shortest interval observed. Full recovery time (FRT) of the $A-V$ node was the shortest $A_{1}-A_{2}$ interval at which $A_{2}-H_{2}$ was equal to $A_{1}-H_{1}$. A-V nodal effective refractory period was the longest $A_{1}-A_{2}$ at which $H_{2}$ failed to occur. A-V nodal functional refractory period was the shortest $\mathrm{H}_{1}-\mathrm{H}_{2}$ attainable. When atrial functional refractory period exceeded A-V nodal effective refractory period, the conduction system was said to be atrial limited and A-V nodal effective refractory period was tabulated as less than atrial functional refractory period. (Fig. 3B). Effective refractory period of the HisPurkinje system was the longest $\mathrm{H}_{1}-\mathrm{H}_{2}$ at which conduction to the ventricles failed to occur. Refractory period of a bundle branch was considered the longest $\mathrm{H}_{1}-\mathrm{H}_{2}$ at which the appropriate surface electrocardiographic pattern of bundle branch block occurred.

\section{ANALYSIS OF DATA}

The 70.patients were divided into six age groups: $<2$ years $(n=$ $10), 3-5$ years $(n=11), 6-10$ years $(n=14), 11-15$ years $(n=$ $12), 16-30$ years $(n=8)$, and $>30$ years $(N=15)$. In the youngest group the age range was 7 months to 2 years, $1.28 \pm 0.46$ (mean \pm $\mathrm{SD})$. In the oldest group the range was 33.77 years, $52.2 \pm 13.72$ (mean \pm standard deviation). Cycle lengths for each age group were divided into ranges: $C_{1}, 1,000-600 \mathrm{msec} ; \mathrm{CL}_{2}, 599-460$ msec; $\mathrm{CL}_{3},<459 \mathrm{msec}$. Means and standard deviations of cycle lengths for each group within each $\mathrm{CL}$ were tabulated. Refractory periods at the three CL's within each age group were determined. Full recovery times of the A-V node within groups of children were determined. Means and standard errors of the means for data in each CL of each age group were tabulated and their statistical significance was found by analysis of variance.

Regression analysis utilizing linear, $\log X, \log Y$, and $\log \mathrm{X}$ and $Y$ models was done on a programming calculator (Wang $700 \mathrm{C}$ series) coupled to an X, Y plotter (Wang 702 series). Refractory periods and $A-V$ node full recovery times were the ordinates and age was the abcissa.

\section{RESULTS}

\section{CYCLE LENGTHS}

The mean values $=1$ SDM of cycle lengths within cycle length ranges for the six age groups are listed in Table 1 . There was no significant difference between groups at $\mathrm{CL}_{1}$ and $\mathrm{CL}_{2}(F>0.25)$. Borderline significant difference was found at $\mathrm{CL}_{3}(F>0.05)$. The number of younger children who could be paced at slower rates, $C L_{1}$, was smaller than older patients because of the faster resting heart rates in the former. At faster rates, $\mathrm{CL}_{3}$, the number of older patients who could be paced was less than in the younger groups, as the former developed Wenckebach periods at slower rates than children.

\section{REFRACTORY PERIODS}

The mean values \pm 1 SEM of atrial effective and functional and A-V nodal effective and functional refractory periods are shown in Table 2. At $C L_{1}$, the longest range, there were not enough observations in the two youngest groups for comparison. The younger groups tended to have shorter values than the older groups.

\section{ATRIAL EFFECTIVE REFRACTORY PERIODS}

Atrial effective refractory periods for each age group within each cycle length range were found to be significantly different from each other. At $\mathrm{CL}_{1}, \mathrm{CL}_{2}$, and $\mathrm{CL}_{3}$ the $F$ values were $<0.001$, $<0.01$, and $<0.001$, respectively (Table 2 ).

\section{ATRIAL FUNCTIONAL REFRACTORY PERIODS}

Atrial functional refractory periods for each age group within each cycle length range were significantly different from each other. At $C L_{1}, C L_{2}$, and $C L_{3}$ the $F$ values were $<0.025,<0.01$, and $<0.001$, respectively (Table 2 ).

\section{A-V NODE FULL RECOVERY TIMES}

A-V node full recovery times were analyzed in patients less than 15 years old. Means \pm 1 SEM are listed in Table 3. There were not enough observations for analysis at $\mathrm{CL}_{1}$. At $\mathrm{CL}_{2}$ there was borderline significant difference $(F<0.05)$ and at $\mathrm{CL}_{3}$ the differences were significant $(F<0.01)$. The younger groups had faster recovery times.

\section{A-V NODE EFFECTIVE REFRACTORY PERIODS}

A-V node effective refractory periods for each age group within each cycle length range were significantly different from each other. At $\mathrm{CL}_{1}, \mathrm{CL}_{2}$, and $\mathrm{CL}_{3}$ the $F$ values were $<0.01,<0.001$, and $<0.001$, respectively (Table 2 ).

\section{A-V NODE FUNCTIONAL REFRACTORY PERIODS}

A-V node functional refractory periods for each age group were significantly different from each other within $\mathrm{CL}_{2}(F<0.001)$ and $\mathrm{CL}_{3}\left(F<0.001\right.$ ). Differences at $\mathrm{CL}_{1}$ were not significant (Table 2).

There were not enough observations of His-Purkinje system or bundle branch refractory periods for analysis in age groups.

\section{REGRESSION ANALYSIS}

At $\mathrm{CL}_{1}$ no fit was significant; however, the number of observations was small. At $\mathrm{CL}_{2}$ atrial effective refractory periods were

Table I. Cycle lengths within cycle length ranges ${ }^{1}$

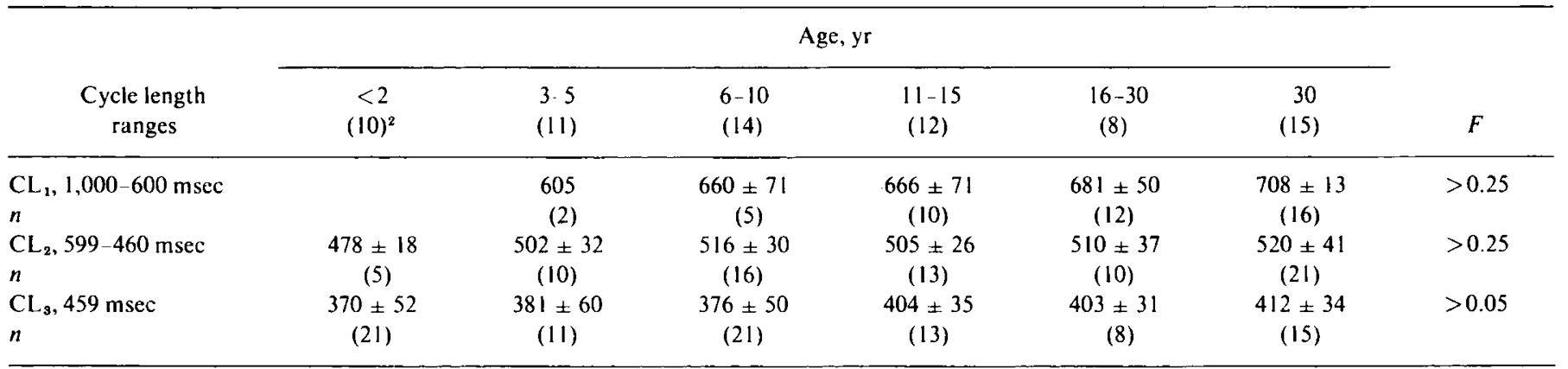

${ }^{1}$ Values of cycle lengths are listed as means in milliseconds \pm 1 SDM. $n$ : number of observations.

${ }^{2}$ Number of patients. 
Table 2. Refractory periods within cycle length ranges and age groups ${ }^{1}$

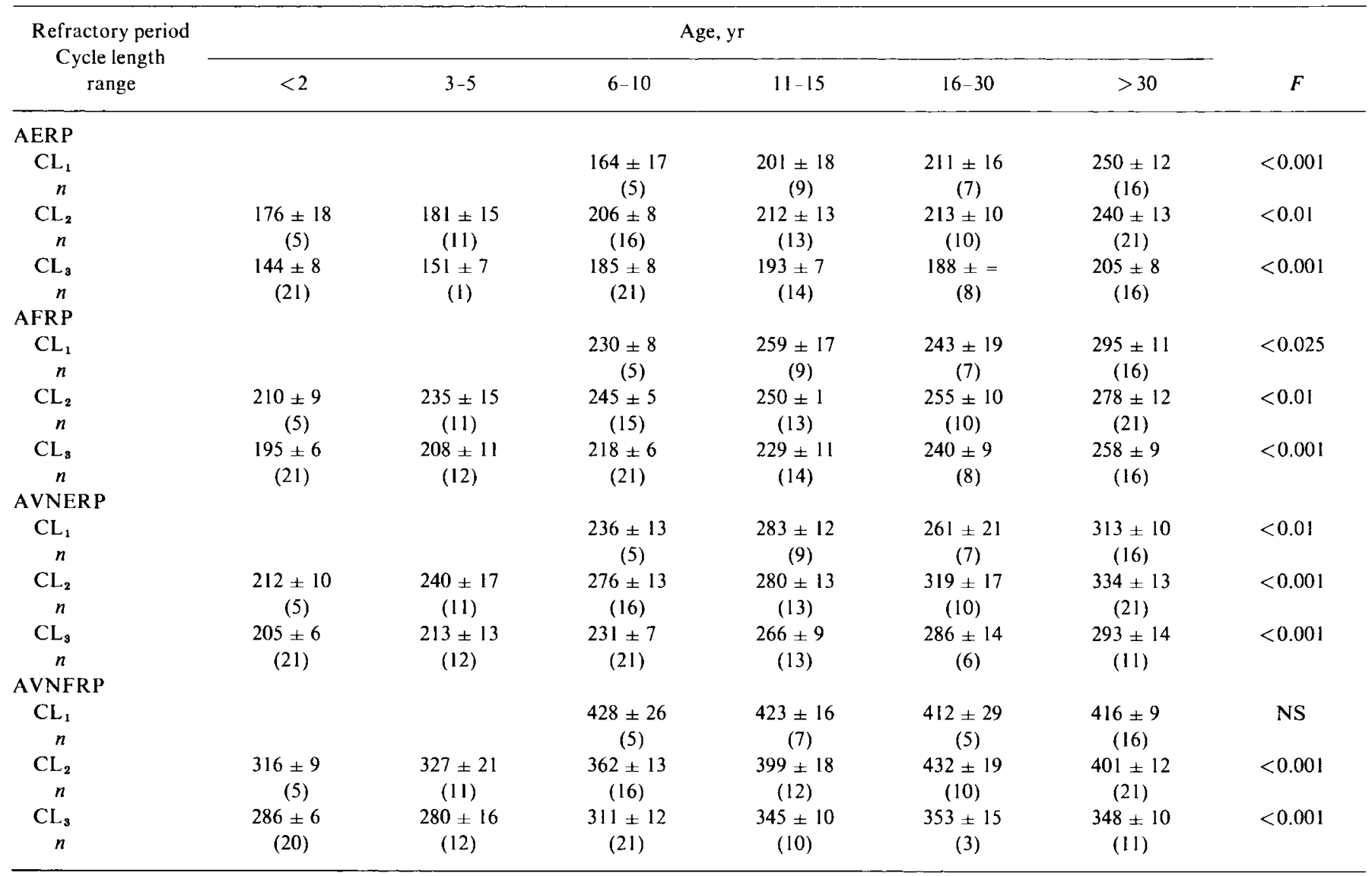

${ }^{1}$ AERP: atrial effective refractory period; AFRP: atrial functional refractory period; AVNERP: A-V nodal effective refractory period; AVNFRP: A-V nodal functional refractory period; $C L_{1}$ : cycle length range $1,000-600 \mathrm{msec} ; \mathrm{CL}_{2}$ : cycle length range $599-460 \mathrm{msec} ; \mathrm{CL}_{3}$ : cycle length range $<459$ msec; $n$ : number of observations; NS: not significant. All values are listed in milliseconds \pm 1 SEM.

Table 3. A-V nodal full recovery time ${ }^{1}$

\begin{tabular}{|c|c|c|c|c|c|c|}
\hline \multirow{2}{*}{$\begin{array}{l}\text { Cycle } \\
\text { length } \\
\text { range }\end{array}$} & \multicolumn{5}{|c|}{ Age, yr } & \multirow[b]{2}{*}{$F$} \\
\hline & $<2$ & 3-5 & $6-10$ & $11-15$ & $16-30$ & \\
\hline $\begin{array}{c}\mathrm{CL}_{2} \\
n\end{array}$ & $\begin{array}{c}376 \pm 27 \\
(5)\end{array}$ & $\begin{array}{c}445 \pm 12 \\
(12)\end{array}$ & $\begin{array}{c}436 \pm 19 \\
(14)\end{array}$ & $\begin{array}{c}463 \pm 8 \\
(9)\end{array}$ & & $<0.05$ \\
\hline $\begin{array}{c}\mathrm{CL}_{3} \\
n\end{array}$ & $\begin{array}{c}310 \pm 10 \\
\text { (17) }\end{array}$ & $\begin{array}{c}341 \pm 19 \\
(8)\end{array}$ & $\begin{array}{c}351 \pm 11 \\
(9)\end{array}$ & $\begin{array}{c}384 \pm 15 \\
(10)\end{array}$ & $\begin{array}{l}370 \\
(2)\end{array}$ & $<0.01$ \\
\hline
\end{tabular}

${ }^{1} \mathrm{CL}_{2}$ : cycle length range $599-460 \mathrm{msec} ; \mathrm{CL}_{3}$ : cycle length range $<459$ msec; $n$ : number of observations. All values are listed in milliseconds \pm 1 SEM.

significant as follows: linear, $P<0.02 ; \log \mathrm{X}, P<0.05 ; \log \mathrm{Y}, P$ $<0.01 ; \log \mathrm{X}$ and $\mathrm{Y}, P<0.02$. Atrial functional refractory period fits were not significant. A-V node full recovery times were significant as follows: linear, $P<0.02 ; \log \mathrm{X}, P<0.01 ; \log \mathrm{Y}, P$ $<0.02, \log \mathrm{X}$ and $\mathrm{Y}, P<0.01$. A-V node effective and functional refractory periods were significant at $P<0.001$ for each equation. At $\mathrm{CL}_{s}$ all variables were significant at $P<0.001$ for each equation.

\section{DISCUSSION}

There is a paucity of information regarding pediatric intracardiac electrophysiology. Many of the studies in the literature describe basic intracardiac intervals and compare the data to adult values. Basic intervals are shorter in children and have been shown to be related to age and heart rate $(1-4,22)$. Abella et al. (1) demonstrated an age-related continuum of basic intracardiac intervals. The present communication expands previous observations on the refractory period relationship to various age groups, infants through adults (7). The population was divided arbitrarily into six groups large enough for meaningful analysis of variance.

As heart rate is inversely related to age $(16,21)$, and as refractory periods are related to heart rate $(5,20)$, faster heart rates in children could account for the shorter refractory periods. Friedman et al. (10) demonstrated shorter refractory periods in isolated lamb ventricular myocardium compared with adult sheep, suggesting that age may be an additional factor. We controlled cycle length variable by pacing the age groups at equivalent rates and found atrial effective and functional and A-V nodal effective refractory periods of all age groups to be significantly different. A-V nodal functional refractory periods were significantly different at $C L_{2}$ and $C L_{3}$. Refractory periods of younger groups were shorter than older groups, and differences were greater through groups 6-10 years. Differences from 11-15 years through $>30$ years were less marked. A-V node full recovery times in the groups examined showed similar trends.

The purpose of this analysis was not to predict refractory periods or $\mathrm{A}-\mathrm{V}$ node full recovery time with age, as there was not enough data. Pilot regression analysis in the children, however, did show significant fits to the mathematical models tested for each variable at $\mathrm{CL}_{s}$ and all but atrial functional refractory periods at $\mathrm{CL}_{2}$. $\mathrm{CL}_{1}$ was not significant; however, numbers of observations were smaller than in other ranges. As there were multiple significant fits, further data presently being collected in our laboratory should elucidate which equation will best describe the observed variables. In the mean time, we feel that tabular form and analysis of variance are useful to see the trends. 
James (14) has demonstrated progressive histologic changes in the conduction system of the human fetus, infant, and young child through 2-3 years of age. He has postulated that the observed remodeling may have electrophysiologic correlates (15). With further aging, Erickson and $\operatorname{Lev}(8,18,19)$ have shown degenerative changes in the conduction system. Our demonstration of the changes in refractory periods with age, particularly in children, is consistent with the concept that electrophysiologic functional changes are related to architectural changes of the conduction system during the aging process.

In addition, there is evidence indicating that fetal newborn, and young mammalian hearts are more sensitive to the chronotropic and inotropic influences of catecholamines. This is felt to be due to the progressive innervation of the young heart and the development of the sympathetic intraneural enzyme systems controlling uptake, binding, and synthesis of norepinephrine in the postnatal period. The $\beta$-receptors respond equally to isoproterenol in fetal, young, and adult animals; however, the response to norepinephrine, the endogenous neurohumor, is exaggerated in fetal, infant, and young animals compared with adults $(9-13)$. Krayer et al. (17) demonstrated that epinephrine shortens effective and functional refractory periods of atrioventricular conduction in the heart-lung preparation of dogs, and Siebens et al. (25) have shown that epinephrine and norepinephrine shorten the refractory periods of atrium and ventricle in the dog. Our findings relate to increased catecholamine sensitivity in juvenile hearts.

In conclusion, this study suggests that atrial and A-V nodal refractory periods and $A-V$ nodal full recovery time increase with age. Previous observations suggest that $A-V$ conduction intervals, $\mathrm{A}-\mathrm{H}$ and $\mathrm{H}-\mathrm{V}$, also are age related $(1-4,20)$. These changes in conduction times and refractory periods with age apparently reflect maturation of the conduction system and may explain the differences in susceptibility to and electrophysiologic manifestations of various arrhythmias in infants, children, and adults.

\section{SUMMARY}

An age-related progression of cardiac refractory periods, independent of cycle length, was observed using atrial extrastimulus technique in 70 patients (age range 7 months to 77 years). The changes with age apparently reflect maturational changes in the conduction system and may explain differences in susceptibility to and electrophysiologic manifestations of various arrhythmias in infants, children, and adults.

\section{REFERENCES AND NOTES}

1. Abella, J B, Teixeira, O., Misra, K. P., and Hastreiter, A. R.: Changes of atrioventricular conduction with age in infants and children. Amer. J. Cardiol.. 30: 876 (1972).

2. Bekheit, S., Morton, P., Murtagh, J. G., and Fletcher, E.: Comparison of sinoventricular conduction in children and adults using bundle of $\mathrm{His}$ electrograms. Brit. Heart J., 35: 507 (1973).

3. Brodsky, S. T., Mirowski, M., Krovitz, J., and Rowe, R. D.: Recordings of His bundle and other conduction tissue potentials in children. J. Pediat., 79: 61 (1971).

4. Cohen, L. S., Samet, P., and Yeah, B. K.: A His bundle electrocardiographic analysis of cardiac conduction in the pediatric and adolescent patient. Amer. Heart J., 89: 311 (1975)

Copyright (C) 1976 International Pediatric Research Foundation, Inc.
5. Denes, P., Wu, D., Dhingra, R., Pietras, R. J., and Rosen, K. M.: The effects of cycle length on cardiac refractory periods in man. Circulation, 49: 32 (1974).

6. Dhingra, R. C., Rosen, K. M., and Rahimtoola, S. H.: Normal conduction intervals and responses in sixty-one patients using $\mathrm{His}$ bundle recording and atrial pacing. Chest, 64: 55 (1973).

7. DuBrow, I, W., Fisher, E. A., Amat-y-Leon, F., Denes, P., Wu, D., Rosen, K. and Hastreiter, A. R.: Comparison of cardiac refractory periods in children and adults. Circulation, 5l: 485 (1975).

8. Erickson, E. E., and Lev, M.: Aging changes in the human atrioventricular node, bundle and bundle branches. J. Gerontol., 7: (1952).

9. Friedman, W. F.: The intrinsic physiologic properties of the developing heart. Prog. Cardiovasc. Dis., 15: 87 (1972).

10. Friedman, W. Cooper, C.. Sonnenblick, E., and Braunwald, E.: Comparison of intrinsic properties of fetal, neonatal and adult cardiac muscle. Circulation, 40(suppl. III): 84 (1969.

11. Friedman, W. F., Pool, P. E., Jacobowitz, D., Seagran, S. C., and Braunwald, E.: Sympathetic innervation of the developing rabbit heart. Circ. Res., 23: 25 (1968).

12. Geis, W. P., Tatooles, C. J., Randall, W. C., and Friedman, W. F.: Influence of adrenal catecholamines on cardiovascular regulation in the newborn. Circulation, 4I(suppl III): 42, (1970).

13. Glowinski, J., Axelrod, J., Kopin, I. J., and Wertman, R. J.: Physiological disposition of $\mathrm{H}^{3}$ norepinephrine in the developing rat. J. Pharmacol. Exp. Ther., $146: 48$ (1964).

14. James, T. N.: Cardiac conduction system: Fetal and post-natal. Amer. J. Cardiol., 25: 213 (1970).

15. James, T. N.: Order and disorder in the rhythm of the heart. Circulation, 47:362 (1973).

16. Jose, A. D., and Collison, D.: The normal range and determinants of intrinsic heart rate in man. Cardiovasc. Res., 4: 160 (1970).

17. Krayer, O., Mandoki, J. J., and Mendez, C.: Studies on veratrum alkaloids. XVI. The action of epinephrine and of veratramine on the functional refractory period of the auriculo-ventricular transmission in the heart-lung preparation of the dog. J. Pharmacol. Exp. Ther., 103: 412 (1951).

18. Lev, M.: Aging changes in the human S-A node. J. Gerontol., 9: 1 (1954).

19. Lev, M.: The normal anatomy of the conduction system and its pathology in atrioventricular block. Ann. N. Y. Acad. Sci., 111: 817 (1964).

20. Mendez, C., Gruhzit, C. C., and Moe, G. K.: Influences of cycle length upon refractory periods of auricles, ventricles and A-V node in the dog. Amer. J. Physiol., 184: 287 (1956).

21. Namin, E. P., and Miller, R. A.: The normal electrocardiogram and vectorcardiogram in children, Chapt. 6. In: D. E. Cassels and R. F. Ziegler: Electrocardiography in infants and Children p. 99 (Grune \& Stratton, Inc., New York 1966).

22. Roberts, N., and Olley, P.: His bundle electrogram in children-Statistical correlation of the atrioventricular conduction times in children with their age and heart rate. Brit. Heart J., 34: 1099 (1972).

23. Rosen, K. M. (Editor): Cardiac electrophysiology symposium. Arch. Int. Med., 135: 387 (1975).

24. Scherlag, B. J., Lau, S. H., Helfant, R. H., Berkowitz, W. D., Stein, E., and Damato, A.: Catheter technique for recording $\mathrm{His}$ bundle activity in man. Circulation, 39: 13 (1969).

25. Siebens, A., Hoffman, B., Ensan, Y., Farrell, J., and Brooks, C.: Effects of L-eprinephrine and L-norepinephrine on cardiac excitability. Amer. J. Phusiol., 175: 1 (1953).

26. Wit, A. L., Weiss, M. B., Berkowitz, W. D., Rosen, K. M., Steiner, C., and Damato, A. N.: Patterns of atrioventricular conduction in the human heart. Circ. Res., 27: 345 (1970).

27. M. Bloom, Philadelphia, Pa.

28. The technical expertise of Mr. Frank Domanszky, Ms. Audra Jarasius, and Mrs Jan Littke and the secretarial assistance of Mrs. Bernice Senger and Mrs. Lorraine Nelsen are gratefully acknowledged.

29. This research was supported in part by The University of Illinois Foundation Goodenberger Medical Grant (2-44-33-66-3-14).

30. Requests for reprints should be addressed to: I. W. DuBrow, M.D., Department of Pediatrics, University of Illinois Hospital, $840 \mathrm{~S}$. Wood St. Chicago, Ill. 60612 (USA).

31. Accepted for publication October 14, 1975. 